\title{
URBAN PARAMETRIC PERCEPTION. THE CASE STUDY OF THE HISTORIC CENTRE OF PERUGIA
}

\author{
F. Bianconi ${ }^{1}$, M. Filippucci ${ }^{1}$, M. Seccaroni ${ }^{1 *}$, C.M. Aquinardi ${ }^{1}$ \\ ${ }^{1}$ Department of Civil and Environmental Engineering, University of Perugia, 06125 Perugia, Italy - fabio.bianconi@unipg.it \\ marco.filippucci@unipg.it marco.seccaroni@unipg.it costanza.aquinardi@gmail.com
}

KEY WORDS: EEG, Eye-tracker, GPS, Perception, Representation, Emotions, DEM

\begin{abstract}
:
The study describes a new approach methodology to detect and represent emotions from signals measured by an Emotiv EPOC cascade. The developed algorithm aims to obtain an analysis of emotions based on EEG data with interpolation of these using the concepts of the circumplex model. This tool will help in the analysis of emotions produced by the atmosphere of an environment in relation to the position, detected by GPS. In addition, the same algorithm will be used to search for a graphic representation of immediate reading, by means of colour association with the output values obtained, to integrate those of gaze analysis obtained by Pupil Player software and position data.
\end{abstract}

\section{INTRODUCTION}

As Leon Battista Alberti stated from the very beginning of his treatise on architecture, architecture always offers "ad vitam bene beat eque agendam faciant" (Alberti, 1443), i.e. it has the original need to be an exclusively positive art, aimed at making people live "better", which is the true aim of the complexity of actions needed to transform a place. Achieving these objectives, however, often remains a random result, in the complexity of assessing the effects of the design choices on man.

In general, places, whether natural or built, have an extraordinary capacity to arouse feelings and reactions in people: a room, a piece of architecture, a square, an entire city, a landscape, are for the people who experience them continuous sources of stimulation and processing of information, but also of emotions. As environmental psychology teaches us (Gibson, 1983), the ecosystem in which we are embedded substantially influences the human experience, affecting behaviour and well-being (Steg et al., 2013). Our way of thinking and acting depends closely on where we are, as well as on who we are: for example, in a very noisy environment we walk faster, we less explore our surroundings, we are less interested in other people. While, where there is silence we are inclined to speak softly, be more respectful of others and maintain greater interpersonal distances (Costa, 2009).

The experience and the contextual elaboration of the concept of place (Norberg-Schulz, 2000) is a cultural process based on sensory reasons, which however goes beyond the empirical stimulus by defining a language that fully encompasses the sphere of the person. Beyond the filters and interpretations of those signals with which the environment speaks to man, there remains the person as a receiver of information, which can be understood as a sensor, where it is possible to "record" those signals received through the impact on his psyche.

The sensory and emotional experience, so linked to images (Mitchell, 1980), is mitigated by the rationality of interpretation (von Balthasar, 1961) which leads us to filter information (Arnheim, 1965) to define patterns, in the need to understand the world in order to orient ourselves, not only spatially but also humanly (Kepes, 1944). This is how figuration was born (Filippucci, 2012), a drawing in mind, based on the primitives of point and line (Filippucci, 2015) that allows space to be read by transforming it into maps (Lynch, 1962). The "good form" (Lynch, 1984) of a place, which is linked to its legibility (Lynch, 1962), will guarantee wellbeing through the satisfaction of the cognitive efforts made to orient oneself, while on the contrary the loss will lead to frustration, stress, inadequacy and rejection. However, this is only one segment of the multiple pieces of information that an environment provokes in humans. This is the reason why, in addition to the structure inherent in figurative interpretation, designating the denotative aspects of phenomenological interpretation, it becomes absolutely central to investigate the impact of the connotative elements (Küller et al., 2009) that can be measured in humans, according to their relationship with places (Schultz et al., 2004), as well as the physiological responses (such as hormonal responses) of people to specific experiences of place (Evans and Wener, 2007).

We thus enter the study of perception, a fundamental term used in the European Landscape Convention to define the concept of landscape: "Landscape" means an area, as perceived by people, whose character is the result of the action and interaction of natural and/or human factors". In our society of communication and images, questioning the issues of landscape (Bianconi and Filippucci, 2019a) therefore means addressing the complexity that arises from the relationships (Bianconi et al., 2018a) that immaterially bind the territory, the environment in which we live, and the person.

The study of the landscape in which this research is grafted is therefore centred on the theme of perceptive analysis, a field of investigation in which to evaluate a holistic multisensory process given by the synaesthetic combination of the different stimuli received by the various actors-spectators. (Böhme, 1995). This field of investigation is developed within representative studies (Bianconi et al., 2018b; Bianconi and Filippucci, 2019b, 2019b), analysing the virtual 'design' of the mind with measurements that, as in physical space, are based on the value of data. In particular, it becomes interesting to evaluate the effects of a place on man

\footnotetext{
* Corresponding author
} 
(Canter, 1977), thus going on to study the action-reaction system readable from its behaviour (Makeig et al., 2009).

A successful combination of architectural/urban survey and neuroscience can then be found (Dupont and Van Eetvelde, 2012; Chen et al., 2019; Neale et al., 2019), so much so that the tools used in the field of neuromarketing (Berčík et al., 2015, 2016; Onay, 2016; de Oliviera and Giraldi, 2017; Dos Santos, 2017) can become useful means of detecting perception and landscape. In order to assess the impact of a place on humans, it becomes interesting to use portable tools for analysing the electrical activity of the brain such as EEG (Gevins et al.; Gramann et al., 2011; Jungnickel and Gramann, 2016; Kim et al., 2018; Kotowski et al., 2018). EEG can detect alpha and beta signals, which are bands of particular interest in pleasure state research (Niemic, 2002): alpha waves, which originate predominantly during relaxed mental states, visible over the parietal and occipital lobes, are related to states of brain inactivation, while beta wave activity is related to an active state of mind, more prominent in the prefrontal cortex (Kandel et al., 2013). Levels of activation of the two cortical hemispheres thus emerge, where left frontal inactivation is an indicator of an abstinence response, which is often linked to a negative state, while right frontal inactivation may be associated with a response approach, thus linked to a positive emotion.

It should be borne in mind that man is a predominantly visual animal: more than $50 \%$ of the neurons in his brain respond to this sensory input (Maffei, 2007). For this reason, it is important to link sensations with the analysis of what the eye grasps (Gregory, 1970), whose fixations can be detected through wearable equipment such as eyetrackers (Schiessl et al., 2003; dos Santos et al., 2015; Weichbroth et al., 2016; Duchowski, 2017).

For each place, by analysing a statistically significant sample of subjects, it is possible to define "fashions" of impacts, assuming a fusion of data that are in any case different (Li et al., 2016), aligned as a function of space and time, in order to define heat maps of psychological sensations (Dufresne et al., 2017; Courtemanche et al., 2018). However, it is not just a matter of recording the stimuli, but a critical analysis of the effects (Goldstein, 2007), which translates into the reading of emotions. In the literature, models have been defined that are capable of interpolating sensory data to derive the prevailing emotions, as is the case with the circumplex model (Posner et al., 2008), first proposed by Russell (Russell, 1980): according to the interpretation of Donovan and Rossiter (Huddleston et al., 2018), actual emotional states can be traced to two main neurophysiological systems, one explaining the valence of the emotion (along a continuum of pleasantness-unpleasantness) and another referring to the corresponding level of physiological activation/deactivation.

The study of the psychological impact on man, however, aims to bring out the correlation with the place, and it is central in this regard to link the analysis to the environmental space that determines these feelings. In the complexity of factors in the field, it becomes fundamental to use expeditious tools for the reconstruction of spatial models that still have the connotative elements, a requirement for which it is suitable to use photomodelling (Filippucci, 2010; De Luca, 2011; Bianconi et al., 2017) based on data present in the network (Weber, 2005).

The analyses of urban and landscape character that can be obtained by combining such systems (Mavros et al., 2012, 2016; Aspinall et al., 2015) thus bring out 'unconscious' emotions by relating what the person is attracted to and its impact on the same person. Analogously it places this emphasis on perception as an analysis of well-being (Bechtel and Churchman, 2002; Badland and Pearce, 2019). It is indeed possible to measure the impact that an environment has on the person in order to assess how these places can create well-being for health (Lee and
Maheswaran, 2011; Byrne et al., 2014; Pedersen Zari, 2015; Schram-Bijkerk et al., 2018), under the assumption that however a place can never be neutral (Goldhagen, 2017).

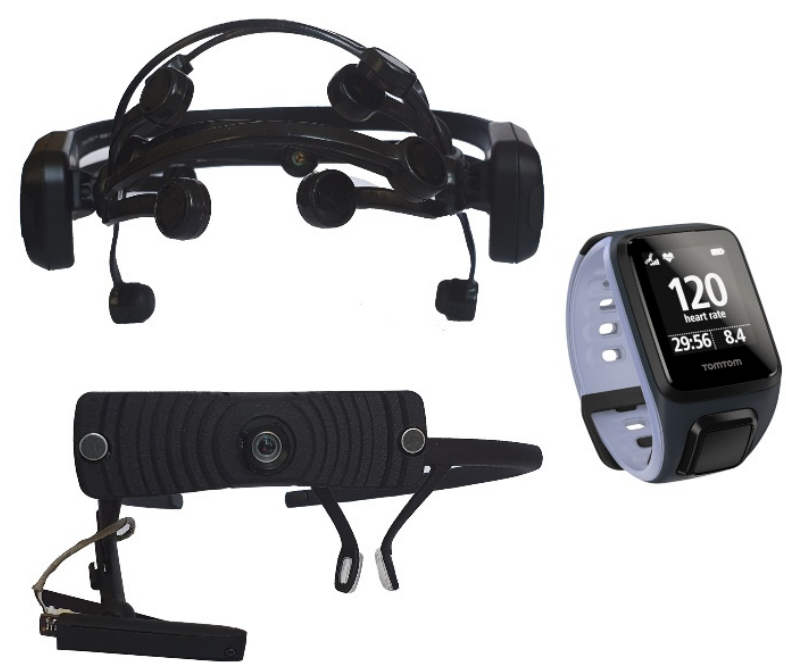

Figure 1- Devices used for experimentation.

\section{MATERIALS AND METHODS}

\subsection{Survey of emotions}

The aim of the survey methodology is to represent the impact of an environment on man. The research developed is proposed as a general methodology, replicable in many different case studies, here ascribed to a paradigmatic case, such as the urban landscape of the historic centre of Perugia.

The instrument used for detecting human impacts is EEG Emotiv Epoc+, which records a data matrix at the time scan. The data collected here are filtered and translated into emotions using the circumplex model, defining a linear combination between the two dimensions of valence (positive or negative) and activation intensity (high or low). The electrodes F3 and F4 correspond to the most frequently used positions for looking at this alpha

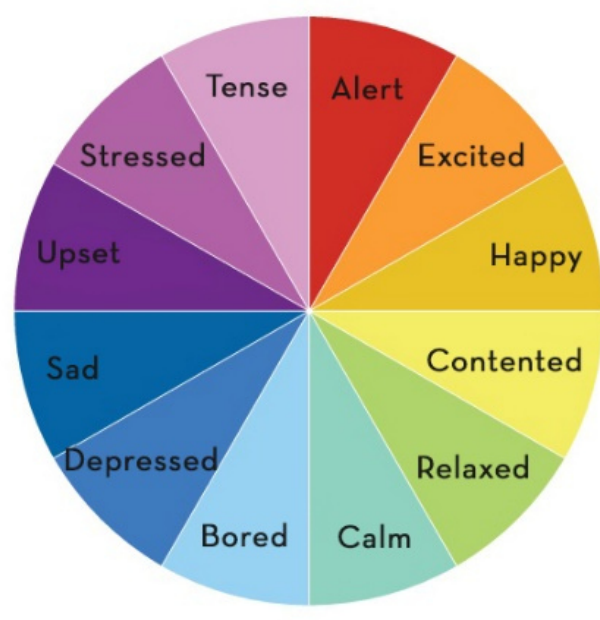

Figure 2 - Circumplex model with the colours used for the representation. 


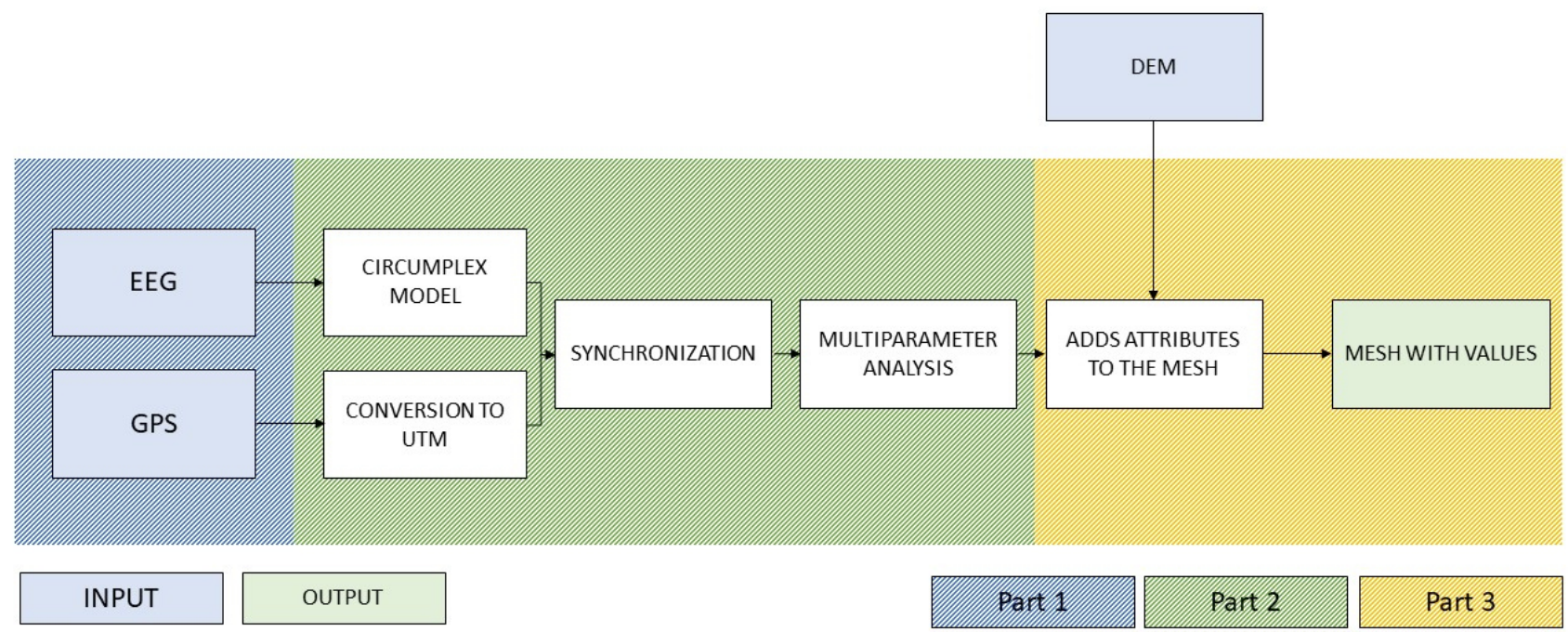

Figure 3 - Logical scheme of the algorithm.

activity, as they are located in the prefrontal lobe, which plays a crucial role in emotion regulation. We therefore estimate valence in a person by calculating and comparing alpha and beta power in F3 and F4 channels:

Valence $=\frac{\alpha(F 4)}{\beta(F 4)}-\frac{\alpha(F 3)}{\beta(F 3)}$

Activation is a metric derived from the measure of Excitement (EXC, short-term arousal), which can be read as a qualification of general mood, rather than acute changes in mental arousal. (Ramirez and Vamvakousis, 2012).

Valence and arousal are the two polar coordinates we use to determine emotions through the circumplex model (Figure 1).

The recording of geographical coordinates was carried out using a TOM TOM Runner2 Cardio watch, which allowed the spatial position to be recorded via GPS at one-second intervals. The GPS data from the watch was converted from WGS84 to the Universal Transverse Mercator Projection (UTM).

The proposed methodology led to match the observer's position detected with the smartwatch with the EEG helmet recording, synchronizing the two timers of the recordings, thus obtaining a space-time association of the experience. In order to have a qualifying data linked to an area, the value used as input in the parametric algorithm was not divided into individual seconds but at the average of every 10 seconds, interpolation necessary to eliminate any singularities.

\subsection{Survey of perceptual attractors}

The survey of attractors and detractors can be divided into two phases: data acquisition and processing.

The first phase was carried out using the eye-track Pupil Core and the acquisition software Pupil Capture.

The acquired data were then analysed by Pupil Player using gaze and fixation metrics.

Gaze points are the basic unit of measurement, one gaze point equals one raw sample captured by the eye tracker. If a series of gaze points is close in time and range, the resultant denotes a fixation.

Fixations are eye movements that stabilise the object of interest on the retina, particularly on the fovea. The duration of the fixations is usually between 100 and $600 \mathrm{~ms}$, a period in which our eyes are locked on a specific object.

\subsection{Generative algorithms for perception surveying}

The data are interpolated into a three-dimensional vector model through a generative modelling add-on linked to Nurbs modelling. The implemented nodal modelling allows the definition of algorithms marked by recursive parametric logic (Schumacher, 2011; Bianconi and Filippucci, 2017; Bianconi et al., 2019) generalisable, so that as a function of different inputs, the corresponding outputs descend (Figure 3 ).

The algorithm in Grasshopper is structured in three parts:

- Data import

- Identification of average value as a function of position

- Assigning values to the mesh

The first step performed by the algorithm generated using Grasshopper is to import the dataset with the raw data. The algorithm is structured in such a way that the file is automatically scalable, in fact it increases the interval of the rows as the number of experiments increases. For an experiment to be valid it is essential that each record is comparable, therefore, a crucial part of the development of the algorithm is the comparison between records. The comparison is done through the GPS position, by finding which points in the recordings are within 20 metres from each other. This value is not random, but due to the approximation of the recordings, since every 10 seconds a person travels an average of 13/20 metres.

Once the neighbouring positions have been identified, the algorithm calculates the average value between the compared positions. At the same time, it identifies the value corresponding to the GPS position in the list of EEG recordings and generates the average value. In this way, an average EEG value is obtained between the various experiments that are around 20 metres apart. The average value of EEG input is made up of two parameters referring to the activation and valence values, which are transposed in a circle that represents the circumplex model thus associating RAW measures in the emotion definitions sought. The summary data is then an average emotion as a function of the average position of the observers. The representation of this process is a mesh coloured according to the colours within the circle diagram. The mesh is coloured by assigning to each vertex the closest corresponding average value (Figures $6 \& 7$ ). 


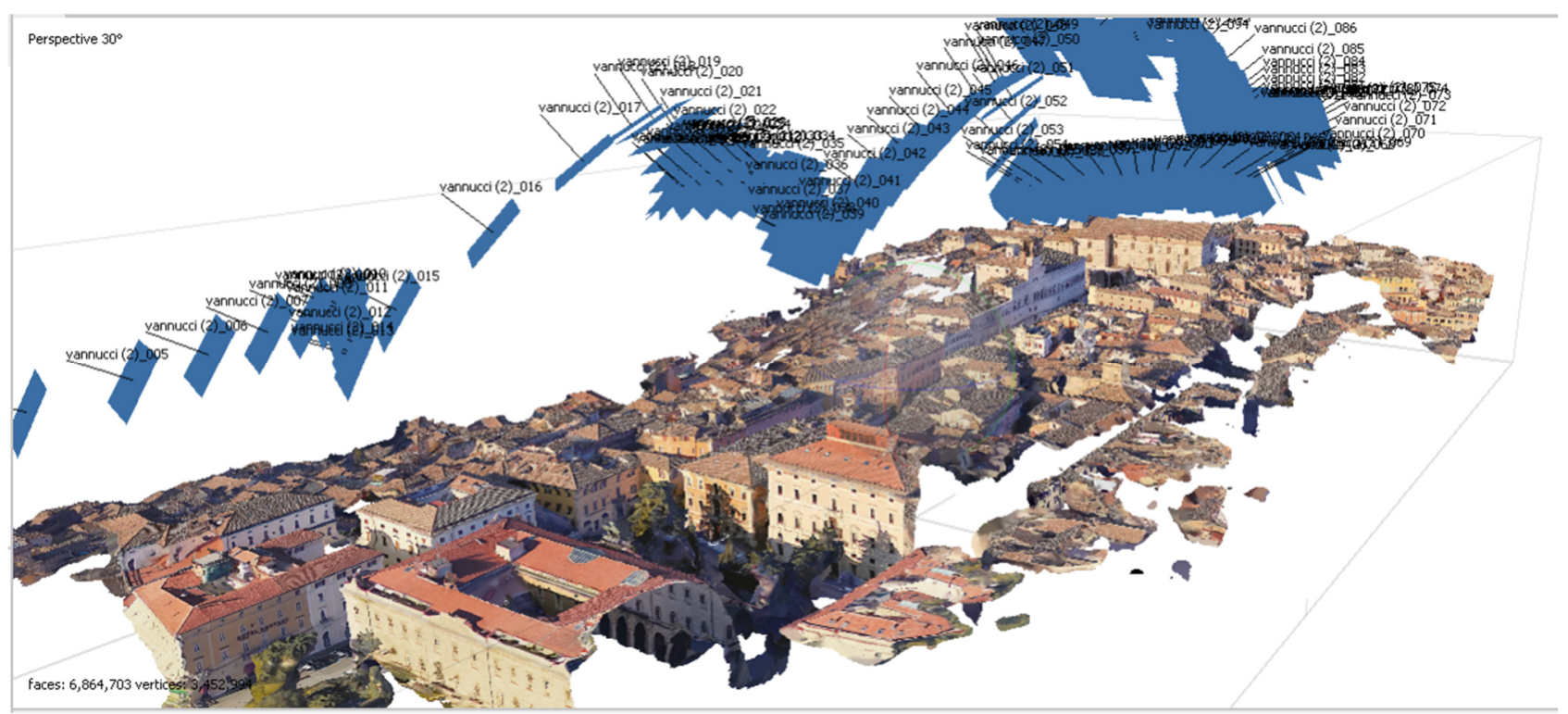

Figure 4 - Creation of the 3D model.

\subsection{D model creation}

The basic input data is the georeferenced mesh from which a $3 \mathrm{D}$ model is obtained by processing sequential images in jpg format, exported from Google Earth Studio. Each image is georeferenced (Latitude, Longitude and Altitude). The photomodelling process is carried out using the Agisoft Metashape software. The 3D model with the resulting texture is exported in obj format (Figure 4).

\section{RESULTS}

\subsection{Empirical experimentation}

The data of the experimentation show as a paradigmatic case the empirical investigations carried out in Perugia (Figure 5).

Fifty-two participants, aged between 25 and 62, were selected for the experiment, of whom 25 men and 27 women. During the navigation experiments, the participants were asked to move from an origin to a destination, simulating natural conditions.

The participation criteria for this study required participants to adhere to the following criteria: (1) no brain or psychiatric disorders; (2) no drug use (3) not to be smokers or habitual drinkers (4) have normal vision or corrected by contact lenses (5) be able to walk for at least 20 minutes (6) have no anxiety in enclosed areas (7) knowledge of the location of the experiment (Wang et al., 2015; Olszewska-Guizzo et al., 2018; Cheon et al., 2019; Elsadek et al., 2019; Neale et al., 2019).

The experiment was divided into two phases: data acquisition in the field followed by data processing using the research algorithm. A watch with GPS data acquisition, eye tracker and EEG on site were used as survey instruments, followed by data processing using the developed algorithm.

For the experiment, participants equipped with eye tracker, EEG and GPS equipment were asked to walk along a designated route. The route covered the main places in the historical centre of Perugia, such as Piazza IV Novembre, Corso Pietro Vannucci, Piazza Italia and the Carducci Gardens. The subjects were asked to walk along Via dei Priori as far as the intersection with the Corso, where data acquisition began. At the same time the recordings are stored in the connected hardware.
Participants were advised to act naturally and were allowed to use their prior knowledge of the area. Each recording lasted about 20-25 minutes, the indicated route was to proceed towards the Carducci Gardens and then back to Piazza IV Novembre to return to the starting point of recording.

The experimentation aims to apply the research tools in an urban context, to understand the emotional aspect in the behaviour whereby. Once the recordings were finished, the data were processed using the search algorithm. The studies revealed the

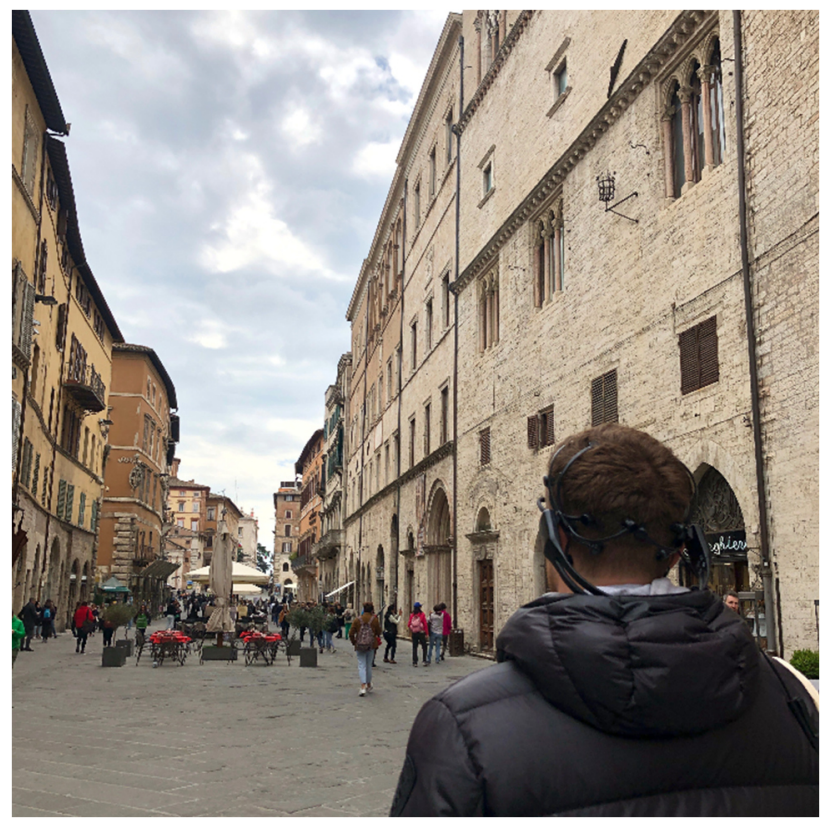

Figure 5 - Data acquisition in Perugia 


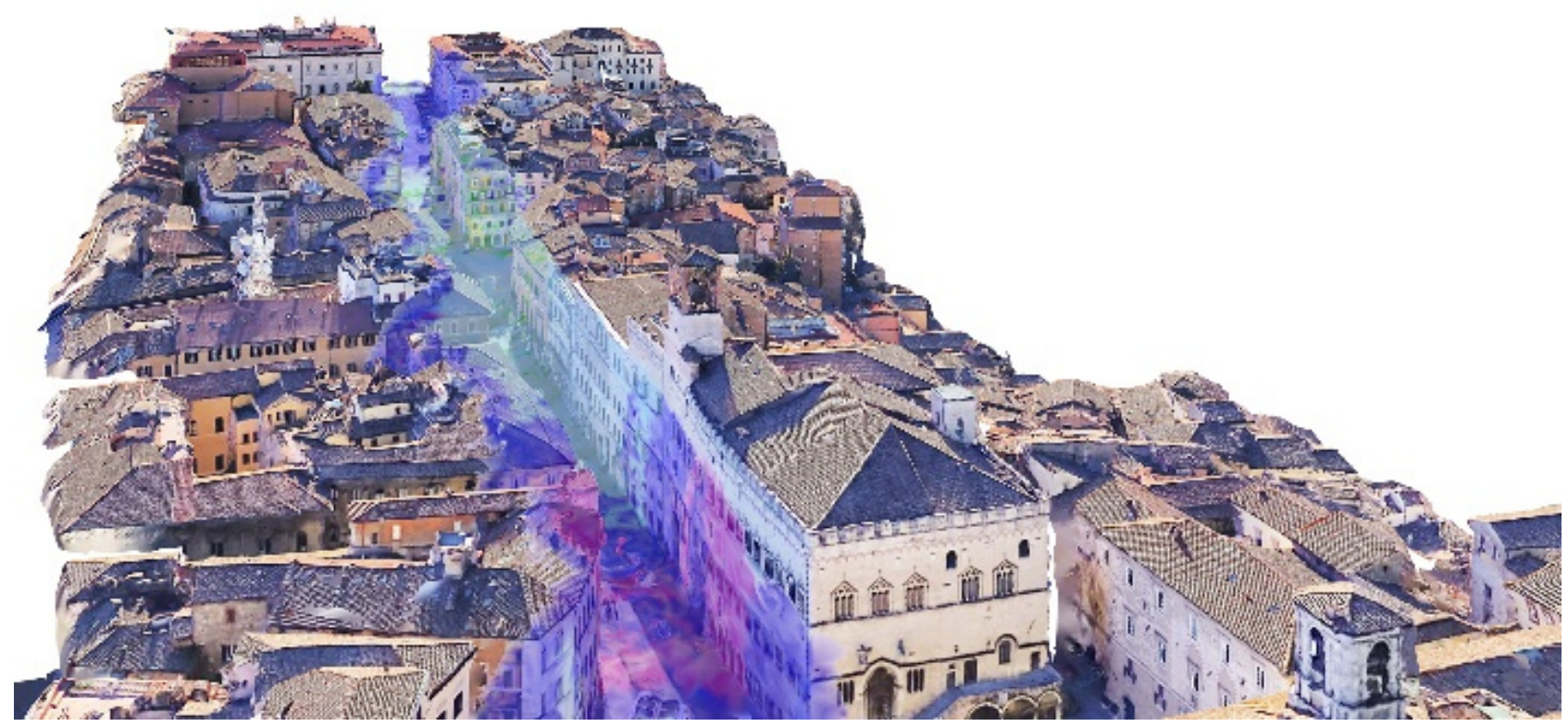

Figure 6 - Representation of emotions through mesh.

degree of neural activity that human subjects experience in anticipation of some spatial experience.

The aim of this work was to discuss how the emergence of new tools for processing and representing data acquired through EEG, offers new opportunities for knowledge and representation of subjective experience and for understanding human emotional states in architectural and urban contexts. In fact, once the data were acquired, they were processed through an algorithm and represented through an analytical model graphically represented by means of a coloured mesh directly on a photorealistic and georeferenced 3D model. The mesh obtained biunivocally associates a colour with each vertex, which in turn is associated with an emotion in relation to Russell's circumplex model on the basis of an average of the values acquired. The three-dimensional model was obtained from the processing of $100 \mathrm{jpg}$ images of 4000x2250 pixel resolution exported from Google Earth Studio through which the path of the camera, from where the views were recorded, is set up as if it was a flight plan for a drone. Each image is georeferenced (latitude, longitude and altitude). The photomodelling process was carried out using the Agisoft Metashape software.

This process provides a representation of the direct measurement of individuals' emotional activity that can support an inclusive, user-centred approach to understanding life in cities.

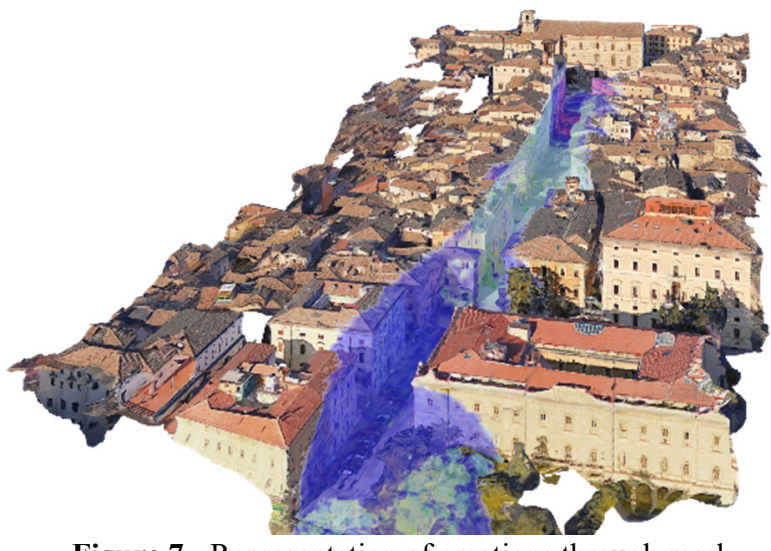

Figure 7 - Representation of emotions through mesh.

\subsection{Discussion of the results}

The data that emerge, processed by means of an algorithm, are averaged over the results of the individual recordings and summarised by means of graphical representations. It is therefore possible to analyse some of the most significant zones/elements, also thanks to the recordings made with the eye tracker (Figure $8)$.

At the beginning of the recording there was a state of stress, which at first analysis could be caused by the initial impact of the subject with the experimentation, moreover, the arrival in Corso Vannucci took place after having walked along Via dei Priori, a road with a notable slope, for a duration of about 10 minutes, this situation of fatigue, added to the entrance in an open space and of greater frequentation could have caused this emotional state. Continuing along Corso Vannucci one notices a change of emotion with colours associated with states of relaxation, calm and contentment as one walks through a protected area, with the presence of tables and chairs for stopping and recreation. When one arrives in Piazza Italia, the state returns to being characterised by the colour violet, which in its shades represents a state of stress and tension. It is noticeable that this square is used as a roundabout with spaces for parking and cars passing through, in fact despite the presence of trees and benches, it is not experienced as an area for pedestrians to stop, but rather as a transit area characterised by the noise of cars and with several pedestrian crossings.

On arrival at the Carducci Gardens, near the trees and benches with spaces dedicated exclusively to parking and near the walls overlooking Viale Indipendenza, there is once again a state of calm, relaxation and contentment, probably also caused by the view of a remarkably extensive panorama. On the return journey, the situations are more or less similar, with a decrease in stress areas at the crossroads with Via dei Priori, for the reasons explained above, and a new increase in tension and stress in the vicinity of Via Calderini, another road dedicated to car traffic. 

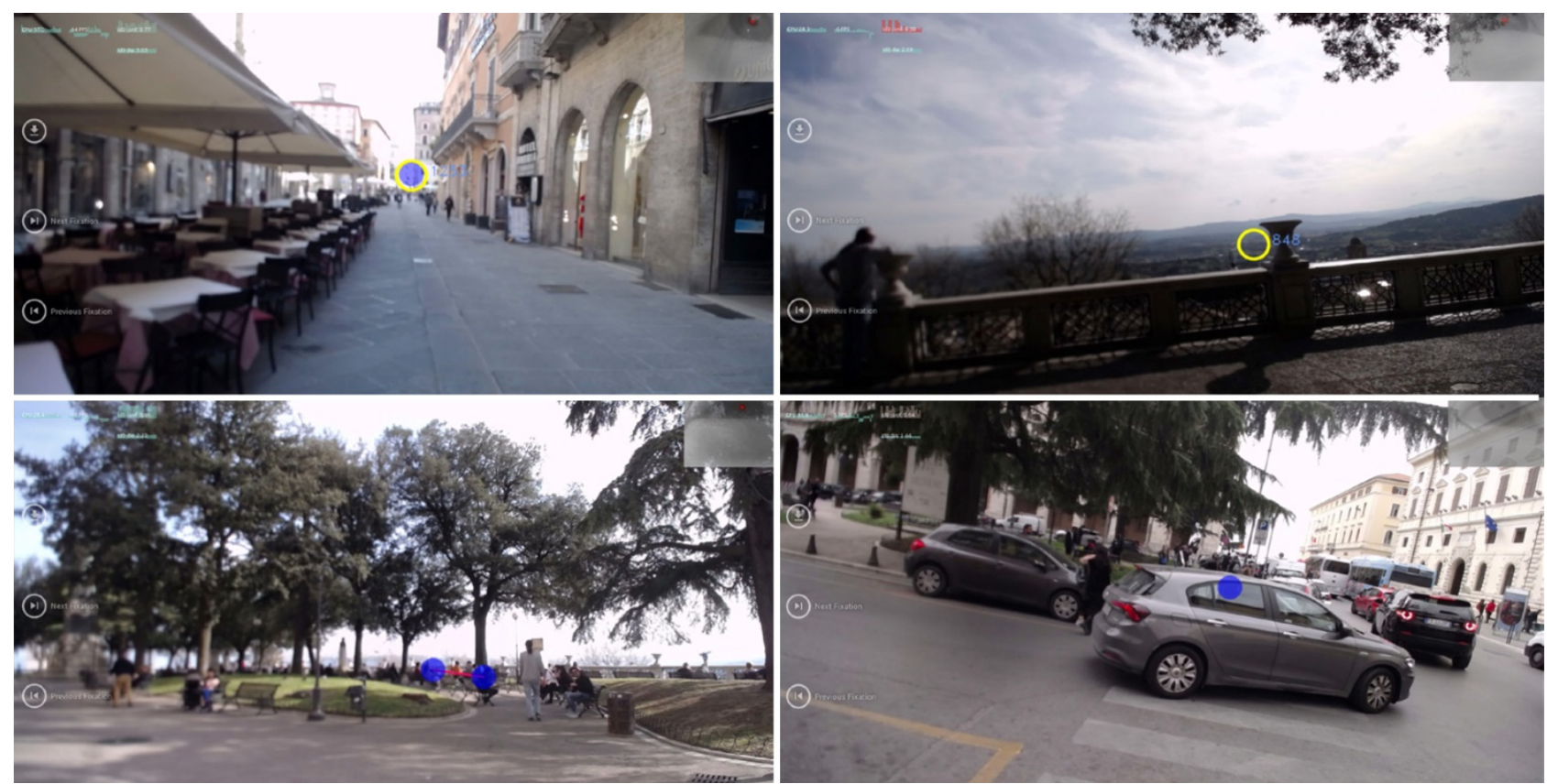

Figure 8 - Gazes and fixations.

\section{CONCLUSIONS}

Surveying perception, assessing the impact of a landscape, analysing which places create wellbeing, defining and naming the emotions felt, are all complex interpretations, often theorised, sometimes intuited, but occasionally quantified and qualified. The relationship between man, space and emotions has been studied through the creation of a replicable digital procedure which, starting from the data, proposes interpretations of the values of the place. Using the tools already tested by the applied sciences of neuromarketing, and in particular using the circomplex model, the affective states of the landscape are classified in an innovative correlation with space. The system identifies the valence of emotions along a continuum of pleasantness-unpleasantness, indicating it through the intensity in terms of physiological activation, with data collected by EEG showing a positive correspondence between the intensity of the neural response and the activation resulting from the vision, detected by eyetracking.

The innovative approach to the representation of emotional states reveals how and how much places affect our well-being and health. The study of the historical urban landscape, with its stratifications, reveals the impact of the evolution of urban space. If the influence on emotions is used by marketing to "sell" better, in the present context the analysis aims to understand where we live best, in order to grasp the underlying qualities. Thus, the atmosphere of a place is analysed, detected in correspondence of the spatial reconstruction with its connotative elements. The transactions detected between the individual and the environment, appear to be the basis for including an evaluation of the impact of the different design solutions, also from the point of view of design heuristics, a process that is projected to determine the architectural and urban quality of a place in correspondence with its impact on the person, always the ultimate goal of design.

\section{REFERENCES}

Alberti LB. 1443. De re aedificatoria. Nicolai Laurentii Alamani: Firenze.

Arnheim R. 1965. Art and visual perception: A psychology of the creative eye. Univresity of California Press: Los Angeles.

Aspinall P, Mavros P, Coyne R, Roe J. 2015. The urban brain: Analysing outdoor physical activity with mobile EEG. British Journal of Sports Medicine 49: 272-276.

Badland H, Pearce J. 2019. Liveable for whom? Prospects of urban liveability to address health inequities. Social Science and Medicine 232: 94-105.

von Balthasar HU. 1961. Herrlichkeit. Schau der Gestalt. Johannes Verlag: freiburg.

Bechtel RB, Churchman A. 2002. Handbook of environmental psychology. J. Wiley \& Sons: New York.

Berčík J, Horská E, Wang WYR, Chen Y-C. 2015. How can food retailing benefit from neuromarketing research: a case of various parameters of store illumination and consumer response. 143rd Joint EAAE/AAEA Seminar.

Berčík J, Horská E, Gálová J, Margianti ES. 2016. Consumer neuroscience in practice: The impact of store atmosphere on consumer behavior. Periodica Polytechnica Social and Management Sciences 24: 96-101.

Bianconi F, Filippucci M. 2017. Generative Education: Thinking by Modeling/Modeling by thinking. In Architectural Draughtsmanship Springer: Cham; 1009-1020.

Bianconi F, Filippucci M. 2019a. Landscape Lab. Drawing, Perception and Design for the Next Landscape Models. Springer Nature: Basingstoke. 
Bianconi F, Filippucci M. 2019b. Visione e disegno . Percezione, rilievo e progetto per nuovi modelli di spazi urbani. In Mondi e modi dell'abitare Per una Sociologia della convivenza Rubbettino: Soveria Mannelli (CZ); 81-104.

Bianconi F, Catalucci S, Filippucci M, Marsili R, Moretti M, Rossi G, Speranzini E. 2017. Comparison between two noncontact techniques for art digitalization. Journal of Physics: Conference Series 882: 12005.

Bianconi F, Filippucci M, Seccaroni M. 2018a. Representing Complexity. Maggioli: Santarcangelo di Romagna (RN).

Bianconi F, Filippucci M, Seccaroni M. 2018b. Rappresentare la percezione: ricostruzione d'ambiente e algoritmi per la valutazione dell'impatto delle forme nel paesaggio. In $3 D$ MODELING \& BIM. Nuove Frontiere DEI s.r.l. TIPOGRAFIA DEL GENIO CIVILE: Roma; 336-349.

Bianconi F, Filippucci M, Buffi A. 2019. Automated design and modeling for mass-customized housing. A web-based design space catalog for timber structures. Automation in Construction 103.

Böhme G. 1995. Atmosphäre: Essays zur neuen Ästhetik. Suhrkamp: Berlin.

Byrne J, Newell J, Wolch J. 2014. Urban Green Space, Public Health, and Environmental Justice: The Challenge of Making Cities 'Just Green Enough'. Landscape and Urban Planning: 234-244.

Canter D V. 1977. The psychology of place. Architectural Press: New York.

Chen J, Wang H, Wang Q, Hua C. 2019. Exploring the fatigue affecting electroencephalography based functional brain networks during real driving in young males. Neuropsychologia 129: 200-211.

Cheon SH, Han S, Kim M, Kwon Y. 2019. Comparison between daytime and nighttime scenery focusing on restorative and recovery effect. Sustainability (Switzerland) 11.

Costa M. 2009. Psicologia ambientale e architettonica. Franco Angeli: Milan.

Courtemanche F, Léger P-M, Dufresne A, Fredette M, LabontéLeMoyne É, Sénécal S. 2018. Physiological heatmaps: a tool for visualizing users' emotional reactions. Multimedia Tools and Applications 77: 11547-11574.

Duchowski AT. 2017. Eye Tracking Methodology. SpringerVerlag: London.

Dufresne A, Courtemanche F, Sénécal S, Fredette M, Léger PM, Labonté-LeMoyne É. 2017. Physiological heatmaps: a tool for visualizing users' emotional reactions. Multimedia Tools and Applications 77: 11547-11574.

Dupont L, Van Eetvelde V. 2012. Landscape perception analysis of built and natural environments using eye tracking: comparison between experts and non-experts. IAPS, 22nd Conference, Abstracts: 254-255.
Elsadek M, Liu B, Lian Z. 2019. Green façades: Their contribution to stress recovery and well-being in high-density cities. Urban Forestry and Urban Greening 46: 126446.

Evans GW, Wener RE. 2007. Crowding and personal space invasion on the train: Please don't make me sit in the middle. Journal of Environmental Psychology 27: 90-94.

Filippucci M. 2010. Nuvole di pixel. La fotomodellazione con software liberi per il rilievo d'architettura. DISEGNARECON 3: $50-63$.

Filippucci M. 2012. Dalla forma urbana all'immagine della città. Percezione e figurazione all'origine dello spazio costruito. Sapienza Università di Roma.

Filippucci M. 2015. Primitive Urbane. Analisi interpretativa dei processi figurativi dell'immagine della città. In Proceedings of the conference held in Turin, Italy, September 17-19, 2015, Novello G, , Marotta A (eds). Gangemi: Torino; 159-168.

Gevins A, Howard R, A Sandoval - US Patent 7551 952, 2009 U. EEG electrode headset. Google Patents.

Gibson JJ. 1983. The senses considered as perceptual systems. Houghton Mifflin: Boston.

Goldhagen SW. 2017. Welcome to Your World. How the Built Environment Shapes Our Lives. HarperCollins: New York.

Goldstein EB. 2007. Sensation and perception. Thomson/Wadsworth: Belmont.

Gramann K, Gwin JT, Ferris DP, Oie K, Jung TP, Lin CT, Liao L De, Makeig S. 2011. Cognition in action: Imaging brain/body dynamics in mobile humans. Reviews in the Neurosciences 22: 593-608.

Gregory RL. 1970. The Intelligent Eye. McGraw-Hill Book Company: New York.

Huddleston PT, Behe BK, Driesener C, Minahan S. 2018. Insideoutside: Using eye-tracking to investigate search-choice processes in the retail environment. Journal of Retailing and Consumer Services 43: 85-93.

Jungnickel E, Gramann K. 2016. Mobile brain/body imaging (MoBI) of physical interaction with dynamically moving objects. Frontiers in Human Neuroscience 10.

Kandel ER, Mack S, Jessell TM, Schwartz JH, Siegelbaum SA, Hudspeth AJ. 2013. Principles of Neural Science. McGraw-Hill : New York.

Kepes G. 1944. Language of vision. Paul Theobald: Chicago.

Kim M, Cheon S, Kang Y. 2018. Use of Electroencephalography ( EEG ) for the Analysis of Emotional Perception and Fear to Nightscapes. : 1-15.

Kotowski K, Stapor K, Leski J, Kotas M. 2018. Validation of Emotiv EPOC+ for extracting ERP correlates of emotional face processing. Biocybernetics and Biomedical Engineering 38: 773-781. 
Küller R, Mikellides B, Janssens J. 2009. Color, arousal, and performance - A comparison of three experiments. Color Research and Application 34: 141-152.

Lee ACK, Maheswaran R. 2011. The health benefits of urban green spaces. Journal of Public Health 33: 212-222.

Li B, Wang Y, Wang K. 2016. Data fusion and analysis techniques of neuromarketing. WIT Transactions on Engineering Sciences 113: $396-404$.

De Luca L. 2011. La fotomodellazione architettonica. Rilievo, modellazione, rappresentazione di edifici a partire da fotografie. Flaccovio Dario: Palermo.

Lynch K. 1962. The Image of the City. MIT Press: Massachusetts.

Lynch K. 1984. Good city form. Harvard-MIT: Cambridge.

Maffei L. 2007. I diversi sentieri della memoria e l'arte visiva. In Immagini della mente: neuroscienze, arte, filosofia, Pinotti A, , Lucignani G (eds). Cortina Raffaello: Milano; 69-81.

Makeig S, Gramann K, Jung TP, Sejnowski TJ, Poizner H. 2009. Linking brain, mind and behavior. International Journal of Psychophysiology 73: 95-100.

Mavros P, Coyne R, Roe J, Aspinall P. 2012. Engaging the Brain: Implications of mobile EEG for spatial representation. Proceedings of the 30th eCAADe Conference 2: 647-656.

Mavros P, Austwick MZ, Smith AH. 2016. Geo-EEG: Towards the Use of EEG in the Study of Urban Behaviour. Applied Spatial Analysis and Policy 9: 191-212.

Mitchell WJT. 1980. The Language of images. University of Chicago Press.

Neale C, Aspinall P, Roe J, Tilley S, Mavros P, Cinderby S, Coyne R, Thin N, Ward Thompson C. 2019. The impact of walking in different urban environments on brain activity in older people. Cities \& Health 00: 1-13.

Niemic CP. 2002. Studies of emotion: A theoretical and empirical review of psychophysiological studies of emotion.

Norberg-Schulz C. 2000. Architecture : presence, language and place. Skira: Losanna.

de Oliviera JHC, Giraldi J de ME. 2017. What is Neuromarketing? A Proposal for a Broader and more Accurate Definition. Global Business and Management Research: An International Journa 9: 19-29.

Olszewska-Guizzo A, Escoffier N, Chan J, Yok TP. 2018. Window view and the brain: Effects of floor level and green cover on the alpha and beta rhythms in a passive exposure eeg experiment. International Journal of Environmental Research and Public Health 15.

Onay O. 2016. A Mathematical Approach to Neuromarketing: A Weapon â Target Assignment Model. International Journal of Academic Research in Business and Social Sciences 6.
Pedersen Zari M. 2015. Ecosystem processes for biomimetic architectural and urban design. Architectural Science Review 58: 106-119.

Posner J, Russell JA, Peterson BS. 2008. The circumplex model of affect. Dev Psychopathol 17: 715-734.

Ramirez R, Vamvakousis Z. 2012. Brain informatic. IEEE Intelligent Systems 26: 16-21.

Russell JA. 1980. A circumplex model of affect. Journal of Personality and Social Psychology 39: 1161-1178.

Dos Santos MA [Ed]. 2017. Applying neuroscience to business practice. Applying neuroscience to business practice.

dos Santos RDOJ, de Oliveira JHC, Rocha JB, Giraldi JDME. 2015. Eye Tracking in Neuromarketing: A Research Agenda for Marketing Studies. International Journal of Psychological Studies 7.

Schiessl M, Duda S, Thölke A, Fischer R. 2003. Eye Tracking and its Application in Usability and Media Research. MMI Interaktiv-Eye Tracking 1: 41-50.

Schram-Bijkerk D, Otte P, Dirven L, Breure AM. 2018. Indicators to support healthy urban gardening in urban management. Science of the Total Environment 621: 863-871.

Schultz PW, Shriver C, Tabanico JJ, Khazian AM. 2004. Implicit connections with nature. Journal of Environmental Psychology 24: $31-42$.

Schumacher P. 2011. Parametricism And the Autopoiesis Of Architecture. Log.

Steg L, Berg V Den, De Groot A. 2013. manuale di psicologia ambientale e dei comportamenti ecologici. FerrariSinibaldi: Milan.

Wang D, Chen Z, Yang C, Liu J, Mo F, Zhang Y. 2015. Validation of the mobile emotiv device using a neuroscan eventrelated potential system. Journal of Medical Imaging and Health Informatics 5: 1553-1557.

Weber S. 2005. The success of open source. Harvard University Press: Cambridge.

Weichbroth P, Redlarski K, Garnik I. 2016. Eye-tracking Web Usability Research 